\title{
Intra-Arterial Infusion of Tirofiban and Urokinase for Thromboembolic Complications During Coil Embolization of Ruptured Intracranial Aneurysms
}

\author{
Rüptüre Intrakraniyal Anevrizmalarn Sarmal Embolizasyonu Strasinda \\ Tromboembolik Komplikasyonları İcin Tirofiban ve Ürokinazın İntra \\ Arteriyel Infüzyonu
}

Lei FENG, Jian CHEN, Chuan-Feng LV, Jun LIU

Jining First People's Hospital, Department of Neurosurgery, Jining, Shandong, China

Corresponding Author: Lei FENG / E-mail: mintgod@163.com

\begin{abstract}
AIM: To investigate the effectiveness and safety of intra-arterial tirofiban and urokinase for thromboembolic complications during detachable coil treatment of ruptured intracranial aneurysms.

MATERIAL and METHODS: Fourteen patients who had a thromboembolic complication during detachable coil treatment of ruptured cerebral aneurysms from May 2011 to October 2013 were enrolled in this study. Within one hour of thrombus formation, patients underwent intra-arterial infusion of tirofiban plus urokinase with digital subtraction angiography monitoring. Blood flow was checked every 5 min with angiography until complete or partial recanalization of the occluded artery occurred.

RESULTS:Of the 14 patients, 10 exhibited complete recanalization immediately after the thrombolytic treatment, and had no neurological dysfunction except one patient with mild hemiplegia. Two patients with partial recanalization exhibited mild neurological dysfunction and one died of cardiac infarction during the recovery period. Two patients had intracranial hemorrhage. In one of these, this was caused by rupture of the aneurysm and the patient died during the thrombolytic treatment. In the remaining patient, intracranial hemorrhage was caused by a puncture of the left posterior internal frontal artery caused by mechanical thrombolysis.
\end{abstract}

CONCLUSION: Intra-arterial administration of tirofiban plus urokinase is an effective and safe treatment for thromboembolism during detachable coil treatment of ruptured intracranial aneurysms.

KEYWORDS: Tirofiban, Urokinase, Coil, İntracranial aneurysm, Thrombolysis

öz

AMAÇ: Rüptüre intrakraniyal anevrizmaların ayrılabilir sarmal ile tedavisi sırasında tromboembolik komplikasyonlar için intra-arteriyel tirofiban ve ürokinazın etkinlik ve güvenirliğini incelemek.

YÖNTEM ve GEREÇLER: Mayıs 2011 ile Ekim 2013 arasında rüptüre serebral anevrizmaların ayrılabilir sarmal ile tedavisi sırasında tromboembolik bir komplikasyon yaşayan on dört hasta bu çalışmaya kaydedildi. Trombüs oluştuktan sonra bir saat içinde hastalara dijital subtraksiyon anjiyografi izlemesiyle birlikte intra-arteriyel tirofiban ve ürokinaz infüzyonu verildi. Kan akışı, anjiyografi ile tıkalı arterin tam veya kısmi rekanalizasyonu oluşuncaya kadar, 5 dakikaya kadar, kontrol edildi.

BULGULAR: 14 hastadan 10'u trombolitik tedaviden sonra tam rekanalizasyon gösterdi ve hafif hemiplejili bir hasta dışında nörolojik bozukluk görülmedi. Kısmi rekanalizasyonlu iki hasta hafif nörolojik disfonksiyon gösterdi ve biri iyileşme döneminde kardiyak infarktüs nedeniyle kaybedildi. İki hastada intrakraniyal kanama vardı. Bunların birinde neden anevrizma rüptürüydü ve hasta trombolitik tedavi sırasında kaybedildi. Diğer hastada intrakraniyal hemorajinin nedeni mekanik tromboliz nedeniyle oluşan sol posterior internal frontal arter yırtılmasıydı.

SONUÇ: Tirofiban ve ürokinazın intra-arteriyel uygulanması rüptüre intrakraniyal anevrizmaların ayrılabilir sarmal ile tedavisi sırasında tromboemboli için etkili ve güvenli bir tedavidir.

ANAHTAR SÖZCÜKLER: Tirofiban, Ürokinaz, Sarmal, İntrakraniyal anevrizma, Tromboliz

\section{INTRODUCTION}

Thromboembolic complication during coil treatment of intracranial aneurysms is a common cause of periprocedural morbidity, occurring in $3 \%$ to $10 \%$ of these procedures (18). The occlusions can occur at or near the coil-parent artery junction or sites distal to the aneurysms.
Fibrinolytic agents such as urokinase is widely used in the clinic for effective thrombolysis, but this agent carry a significant risk of cerebral hemorrhage, which can be lethal. Thus the application of urokinase is greatly restricted during endovascular coiling of these cases, and a new method must be found to reduce the risk of intracranial 
hemorrhage. Glycoprotein Ilb/IIla receptors play a key role in maintaining physiological hemostasis and in pathologic thrombus formation.Glycoprotein Ilb/Illa is the final common component of platelet aggregation(5). Tirofiban, which is a relatively short-acting and reversible glycoprotein $\mathrm{Ib} / \mathrm{llla}$ receptor inhibitor, have been used widely to treat patients with acute coronary syndrome.

Traditionally, a glycoprotein IIb/llla inhibitor is used for preventing platelet aggregation. Superselective intra-arterial administration of tirofiban are an effective method for treating acute ischemic complications during interventional treatment of aneurysms, ruptured or non-ruptured $(3-5,7,13$, 17). These inhibitors exert their thrombolytic action via many mechanisms including: 1) inhibiting platelet aggregation, resulting in a reduced thrombus size and a platform for further thrombin synthesis; 2 ) preventing local release of inhibitors for thrombolysis from platelets; 3) promoting endogenous thrombolysis by breaking down aggregated platelets; and 4) reducing platelet-mediated clot retraction and the gel elastic modulus(12).

One such glycoprotein Ilb/Illa inhibitor is tirofiban. Tirofiban has a short half-life, a low incidence of hemorrhage, and is widely used in coronary interventional treatment (10, 14). It has been reported that tirofiban dose-dependently inhibited platelet aggregation induced by various stimuli, and can decompose the fresh thrombus, even the fibrin-rich thrombus. In a small non-randomized and non-blinded trial containing 19 patients with acute middle cerebral artery occlusion (Thrombolysis in Myocardial Infarction [TIMI] grade 0 to 1$), 13$ (68\%) patients exhibited recanalization with TIMI grade 2-3 after intravenous administration of recombinant tissue plasminogen activator followed by tirofiban at reduced dosages. At the 1-week follow-up, the ischemic region was obviously reduced, and the patients' neurological symptoms improved with no symptomatic hemorrhage (15). Baik et al. (2) reported that intra-arterial tirofiban infusion resulted in a good functional outcome in 3 cases of ischemic stroke. In addition, Jin Sue Jeon (4) found that intra-arterial tirofiban infusion results in a recanalization rate of 3 in 4 patients with total occlusion in myocardial infarction (TIMI) grade III and 5 of 6 with partial occlusion in TIMI grade III recanalizations during endovascular treatment of intracranial aneurysms. Eight patients showed good recovery, with a modified Rankin Scale (mRS) score of 0 and one showed poor outcome (mRS 3 and 6). There was no hemorrhagic or hematologic complication. These results suggest that intra-arterial tirofiban infusion is an effective and safe treatment for acute thromboembolism.

A combination of tirofiban and urokinase theoretically might potentiate thrombolytic effects and reduce the dosages of each drug, thus reducing the risk of hemorrhage. In this study, we evaluated the effectiveness and safety of intra-arterial urokinase plus tirofiban in 14 patients who, from May 2011 to October 2013, had a thromboembolic complication during detachable coil treatment of cerebral aneurysms.

\section{MATERIAL and METHODS}

\section{Patients}

This retrospective study included 14 patients ( 8 men and 6 women) with cerebral aneurysms, who had a thromboembolic complication during Guglielmi detachable coil treatment at the Department of Neurosurgery of Jinan No. 1 People's Hospital from May 2010 to October 2012. The average age of the patients was $61.1 \mathrm{y}$ (range, 41-78 y).

All patients were hospitalized due to spontaneous subarachnoid hemorrhage (SAH). The patients presented symptoms of SAH such as sudden headache, nausea, and vomiting, and $\mathrm{SAH}$ was confirmed by cranial computed tomography (CT). Patients were diagnosed as ruptured cerebral aneurysmal by digital subtraction angiography (DSA). Interventional embolization was performed at the request of the patients.

The Hunt-Hess classification of SAH was used to describe the preoperative severity of bleeding: grade $0(n=3)$, grade I $(n=2)$, grade II $(n=6)$, or grade III $(n=3)$. Multiple aneurysms were present in 2 cases, including one case with aneurysms in the left anterior communicating artery and the M1 segment of the left middle cerebral artery, and one case with aneurysms in the left anterior and posterior communicating arteries. A single aneurysm occurred in the basilar artery bifurcation $(n=1)$, the anterior communicating artery $(n=2)$, the posterior communicating branch of the internal carotid artery $(n=5)$, the pericallosal artery $(n=2)$, and the middle cerebral artery bifurcation $(n=2)$. The size of the aneurysms ranged from 0.3 to $0.7 \mathrm{~cm}$ in diameter. The necks of the aneurysms were $<0.4$ $\mathrm{cm}$. Nine patients had hypertension, 5 patients had diabetes, and 3 patients had atherosclerosis. All patients underwent cranial CT to exclude intracranial hemorrhage.

In 2 cases, cerebral angiography found multiple arterial stenosis and plaques in the brain and neck. Distal occlusion of the $M 1$ segment of the left middle cerebral artery was found during subsequent guided catheter placement. In one case with an aneurysm in the posterior communicating branch of the left internal carotid artery, Guglielmi detachable coils failed to retrieve, and repeated electrical detachment caused thrombosis in the internal carotid artery. In two cases, thrombosis was caused by detached coils from the aneurysmal sac into the parent artery. In two cases, the middle cerebral artery was occluded after stent-assisted embolization of aneurysms of the posterior communicating branch of the internal carotid artery. In five cases, thrombosis was caused by prolonged intravascular intervention due to vascular tortuosity. Insufficient anticoagulation and basilar artery thrombosis occurred in one case, and thrombosis in the $\mathrm{M} 1$ and $\mathrm{A} 2$ segment was found in one case.

\section{Treatment}

After acute thromboembolization was found during surgery, embolization of the aneurysm was completed first, and then thrombolysis as follows. A microcatheter was inserted into the thrombus and its distal end, and the precise size, 
length, and location of the thrombus were visualized using microangiography.

Tirofiban and urokinase were alternately infused via the microcatheter. The distal, middle, and proximal parts of the thrombus were each injected with $1 / 3$ of the dose. The loading dose of tirofiban was $10 \mu \mathrm{g} / \mathrm{kg}$. Tirofiban $(4 \mu \mathrm{g} / \mathrm{kg}$ dissolved in $30 \mathrm{~mL}$ normal saline) and urokinase (500000 $\mathrm{U}$ in $50 \mathrm{~mL}$ normal saline) were infused at a rate of $1 \mathrm{~mL} / \mathrm{min}$. The blood flow was checked every $5 \mathrm{~min}$ with microangiography. If the blood flow in the embolized artery was reestablished, thrombolysis was stopped. If not, tirofiban $(1 \mu \mathrm{g} / \mathrm{kg})$ and urokinase $(250000 \mathrm{U})$ were administered. The termination dose of tirofiban and urokinase was $5 \mu \mathrm{g} / \mathrm{kg}$ and $800000 \mathrm{U}$, respectively. After the treatment, heparin was not neutralized, and the artery sheath was removed $6 \mathrm{~h}$ later.

\section{Intraoperative and Postoperative Management}

Continuous electrocardiography was performed and blood pressure and oxygen saturation were routinely monitored during and after the operation. Blood pressure was closely monitored and was controlled with drugs to maintain below 180/100 $\mathrm{mmHg}$ for $48 \mathrm{~h}$. Cranial CT was performed immediately and $24 \mathrm{~h}$ after the operation, or whenever the patient's condition changed, to check for cerebral infarction and intracranial hemorrhage. After the surgery, tirofiban was intravenously injected via a micro-pump at $0.1 \mu \mathrm{g} \cdot \mathrm{kg}^{-1} \cdot \mathrm{min}^{-1}$ for 24 to $36 \mathrm{~h}$. Patients underwent appropriate rehabilitation treatment after their condition stabilized.

\section{Clinical Evaluation}

Recanalization of the cerebral artery was assessed on the angiogram as follows: grade 0, no perfusion with no blood flow in the distal end of the thrombus; grade 1, no appearance of contrast agents in the distal vasculature without improving perfusion; grade 2, partial recanalization with perfusion in $<50 \%$ of the ischemia region; and grade 3 , complete or nearly complete recanalization with full perfusion of the ischemia region.

All patients were evaluated one month after thrombolytic therapy with the Glasgow outcome scale (GOS) as: 1, death; 2, vegetative state; 3 , severe disability (patients were conscious but depended on others for daily support); 4, mild disability (patients were disabled but independent); and 5, good recovery (patients resumed normal activities). The GOS was dichotomized into a good outcome (GOS 4-5) or a poor outcome (GOS 1-3).

\section{RESULTS}

Of the 14 patients, 10 patients exhibited complete recanalization at Gonner grade 3 immediately after the thrombolytic treatment. No intracranial hemorrhage was observed on cranial CT performed $24 \mathrm{~h}$ after the operation. Of the 10 patients, one exhibited mild hemiplegia, but was able to live independently, and the other 9 patients had no obvious neurological dysfunction (Figure 1A-D).
One patient exhibited partial recanalization at Gonner grade 2 , and a small amount of residual plaque remained after the thrombolytic treatment. This patient showed no intracranial hemorrhage on cranial CT performed $24 \mathrm{~h}$ after treatment, but exhibited mild neurological dysfunction and died of cardiac infarction during the recovery period (Figure $2 A, B$ ).

In one case of Gonner grade 2, the left posterior internal frontal artery was punctured by a microguide wire intraoperatively. Heparin was neutralized with protamine and the thrombolytic treatment was stopped immediately. Cerebral angiography showed that complete recanalization occurred in the trunk of the occluded artery, and the distal branch of the anterior cerebral artery exhibited slow circulation (Figure 3A-F). Cranial CT performed immediately after the operation showed that intracranial hemorrhage occurred in the left frontal lobe. The patient had paralysis on the left limb, and was discharged with improved symptoms after 3 months of conservative treatment.

In one case with partial recanalization, Gonner grade 2, cerebral infarction, and acute brain edema were observed on cranial CT performed $48 \mathrm{~h}$ after the procedure. The patient underwent decompressive craniectomy, and exhibited paralysis of the right limb 3 months after the operation (Figure 4A-H).

In one case with loose packing of the aneurysm, the patient died of the ruptured aneurysm during the thrombolytic treatment (Figure 5A,B).

All patients were evaluated using GOS one month after the thrombolytic therapy. Of the 14 patients, 10 patients had a good outcome, including 2 patients with GOS 4, and 8 patients with GOS 5. Four patients had a poor outcome, including 2 with GOS 1 and 2 with GOS 3.

\section{DISCUSSION}

In the present study we evaluated the effect of intraarterial urokinase plus tirofiban in 14 patients who had thromboembolism during coil treatment of ruptured cerebral aneurysms. We found that 10 patients had complete recanalization with no intracranial hemorrhage. Two patients exhibited partial recanalization, and two patients had intracranial hemorrhage. Our findings suggest that intraarterial infusion of tirofiban plus urokinase is an effective and safe method for thromboembolism occurring during coil treatment of ruptured intracranial aneurysms.

Consistent with our findings, Jeong et al. (5) reported that thromboembolisms developed in 22 of 346 intracranial aneurysms were treated with coiling and were treated by use of intra-arterial tirofiban $(n=11)$ or abciximab $(n=11)$ infusion. Immediate and follow-up recanalization rates for intra-arterial abciximab $(72.7 \%, 100 \%)$ and tirofiban $(90.9 \%$, $100 \%)$ appear to be similar or superior to those reported[5 ]. No hemorrhagic complications were demonstrated in either group. Mangiafico et al. (9) reported that of 21 patients with major cerebral artery occlusion (National Institutes of Health 

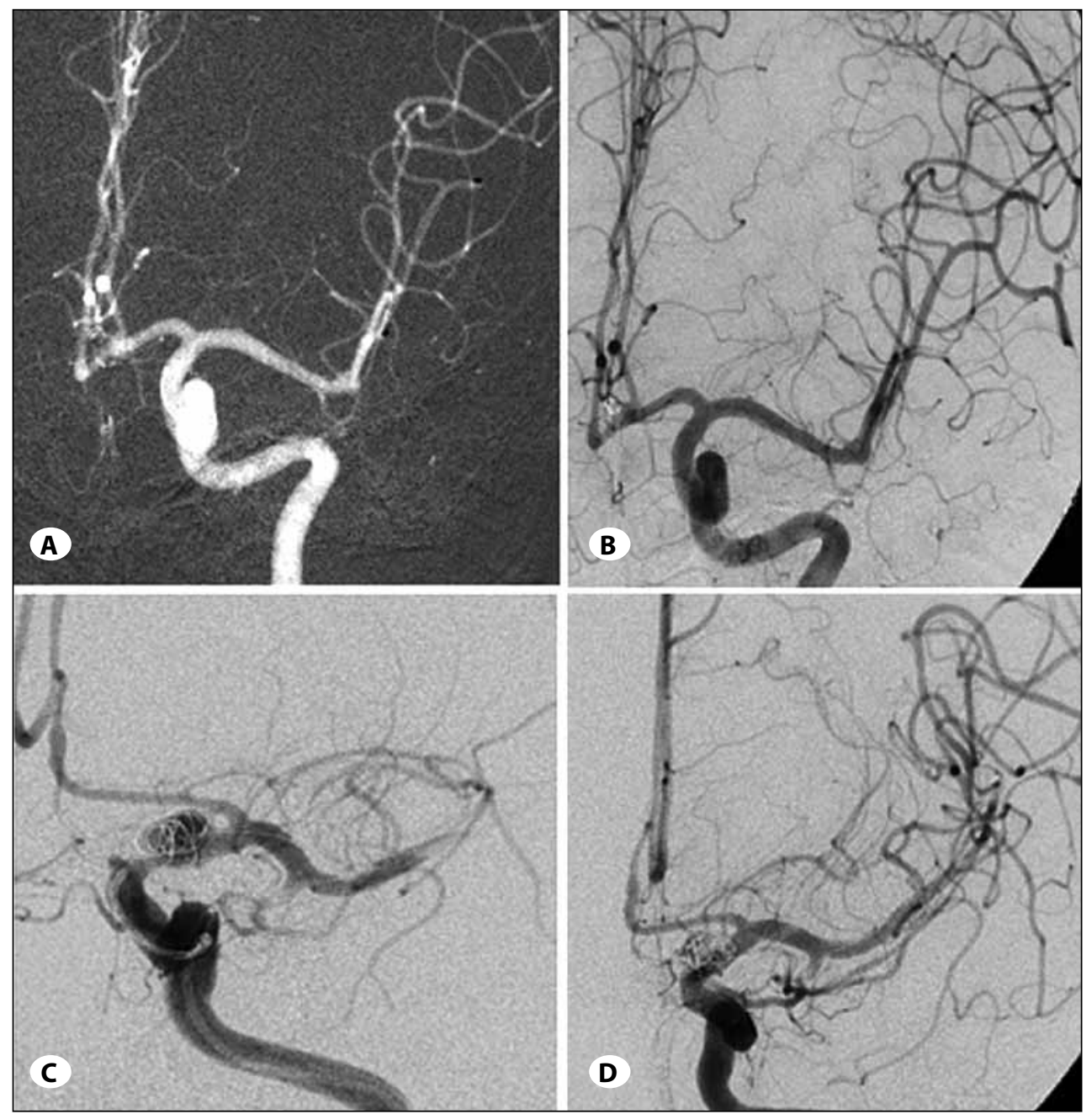

Figure 1: Coil interventional embolization (A, B) compared with stent assisted coil embolization (C, D) prior to and after thrombolytic treatment. a) and b) Left internal carotid artery angiogram, anterior-posterior projection in a patient with complete recanalization immediately after the thrombolytic treatment. A) Thromboembolic occlusion of a parietal branch of the left middle cerebral artery and a microcatheter navigated proximal to the affected site. B) After a local, low-dose, intra-arterial infusion of tirofiban through the microcatheter, digital subtraction angiogram shows resolution of the thrombus with patency of distal arterial branches. c) and d) Angiogram of another patient treated with a stent. C) A self-expanded stent was advanced to the level of the aneurysm orifice. Acute thromboembolism was noted in the left M1 segment of the middle cerebral artery during the coil placement. D) Angiogram obtained $30 \mathrm{~min}$ after a bolus administration of tirofiban shows complete resolution of the thrombus.

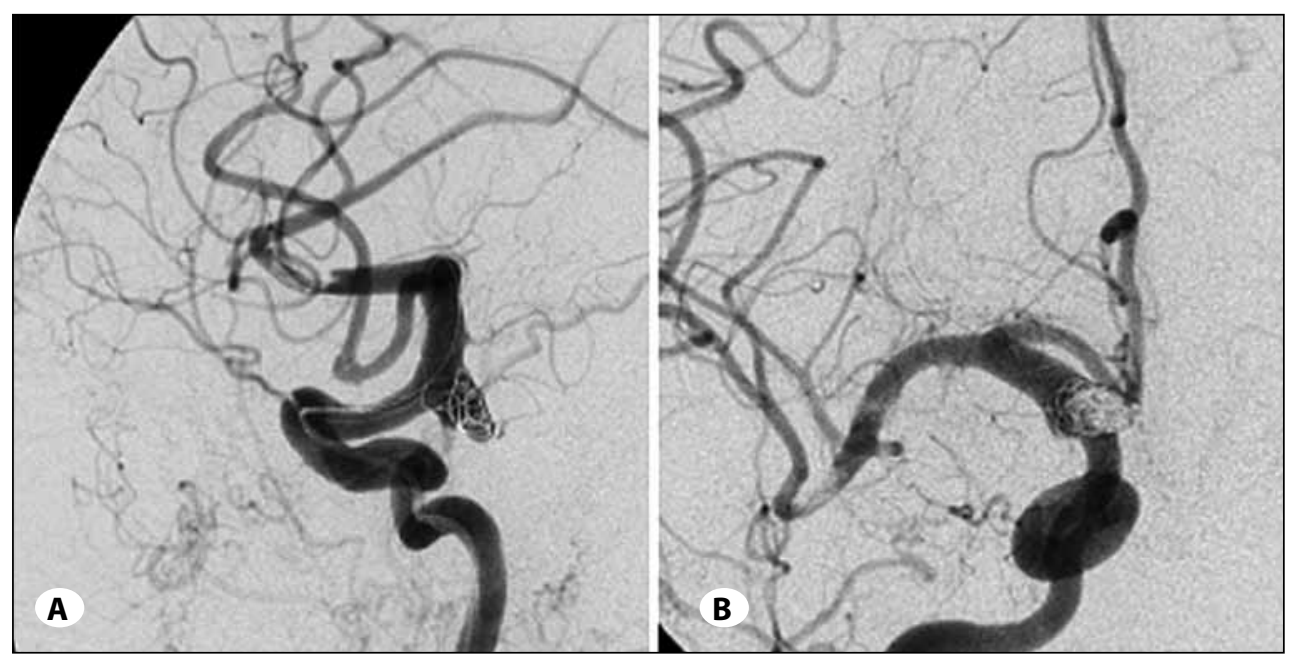

Figure 2: Right internal carotid artery with filling defect in the $\mathrm{M} 1$ segment. A) Digital subtraction angiogram shows thrombus formation.

B) After intra-arterial infusion of tirofiban via microcatheter, partial recanalization with residual plaque is achieved. 
Stroke Scale (NIHSS) score $\geq 18$ ), immediate recanalization occurred in 17 patients with TIMI grade 2-3 after an intravenous bolus of tirofiban followed by intra-arterial administration of urokinase. Complete or nearly complete recanalization (TIMI 3-4) was confirmed by digital subtraction angiography in 14 patients. In patients with major cerebral artery occlusions, a combination of intravenous tirofiban with superselective intra-arterial urokinase effectively reestablished vessel patency, improved neurological function, and reduced complications (9). In addition, of 21 patients with cerebral artery occlusion, intracranial hemorrhage and subarachnoid hemorrhage occurred in 5 (24\%) patients after a combination of intravenous tirofiban and intra-arterial urokinase (9).

Intracranial hemorrhage may be related to symptomatic fibrinolysis caused by intravenous injection of tirofiban.
However, compared with intravenous injection, intra-arterial administration can reach a higher local concentration at the thrombus site with a lower dose, thereby reducing systemic fibrinolysis $(2,5,8)$. In the present study, intra-arterial tirofiban was applied, and only 2 (14\%) of 14 patients had intracranial hemorrhage. Because intra-arterial access a smaller total dose of the drug is expected to be effective, and, as a result, dose-dependent complications such as cerebral hemorrhage may be reduced. Therefore, a combination of intra-arterial administration of tirofiban and urokinase may be a successful method for effecting thrombolysis. Regarding cost-effectiveness and safety, the lower dose of tirofiban and urokinase that was used may be more beneficial.

In the present study, intra-arterial tirofiban infusion did not result in recanalization in the distal branch of the middle
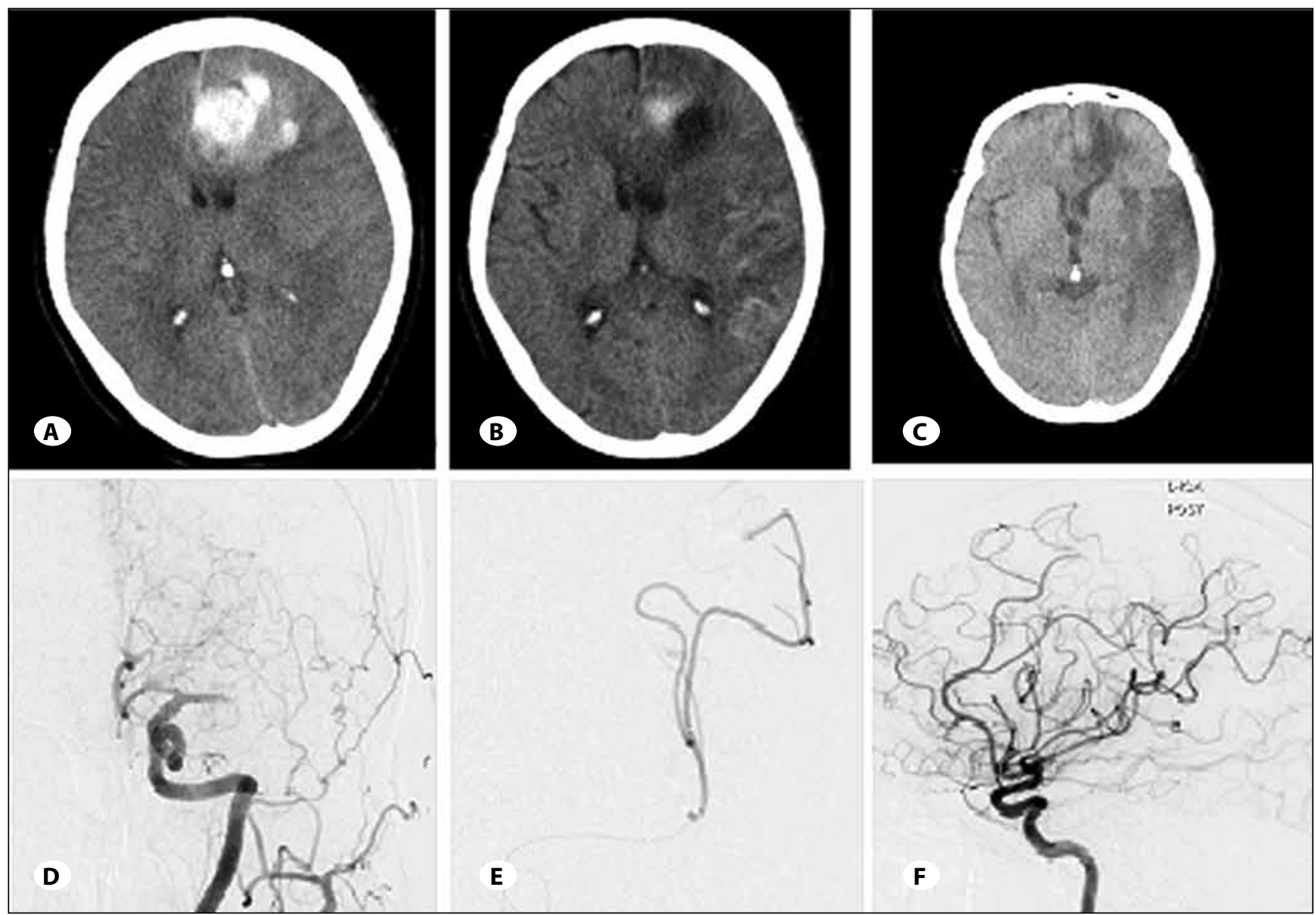

Figure 3: Intracranial hemorrhage and hematoma due to intraoperative puncture of left posterior internal frontal artery, Gonner grade 2. A) Cranial CT performed immediately after intra-arterial tirofiban + urokinase thrombolytic treatment shows a hematoma in the frontoparietal lobe. B) CT performed one month after the thrombolytic treatment shows dissolution of the hematoma. C) CT performed 3 months after the thrombolytic treatment shows complete absorption of hematoma and mild edema in the frontal, parietal, and temporal lobes without midline shift and compression deformation of the lateral ventricle. D) Right internal carotid artery angiogram, anterior-posterior projection. Digital subtraction angiogram shows a filling defect in the M1 segment of the right middle cerebral artery and the A2 segment of the right anterior cerebral artery, indicating thrombus formation. E) Angiogram shows intraarterial infusion of tirofiban via the microcatheter for thrombolysis. F) Right internal carotid artery angiogram, lateral projection. After the bolus administration of tirofiban, digital subtraction angiogram shows complete resolution of the thrombus in the right middle cerebral artery with a filling defect in the branch of the posterior medial frontal artery. 
cerebral artery in 2 patients, and cerebral angiography showed atherosclerotic signs such as stenosis and atherosclerotic plaques in the cerebral artery of these patients. This is likely due to chronic activated thrombus that was refractory to tirofiban treatment, or accessibility of tirofiban was lacking in the distal branch because of occlusion of M1/M2 segments. In addition, the higher blood pressure in the trunk of the middle cerebral artery allows the broken thrombus to move to the distal branches where microcatheters are inaccessible. Because the local collateral blood vessels are not rich, the concentration of
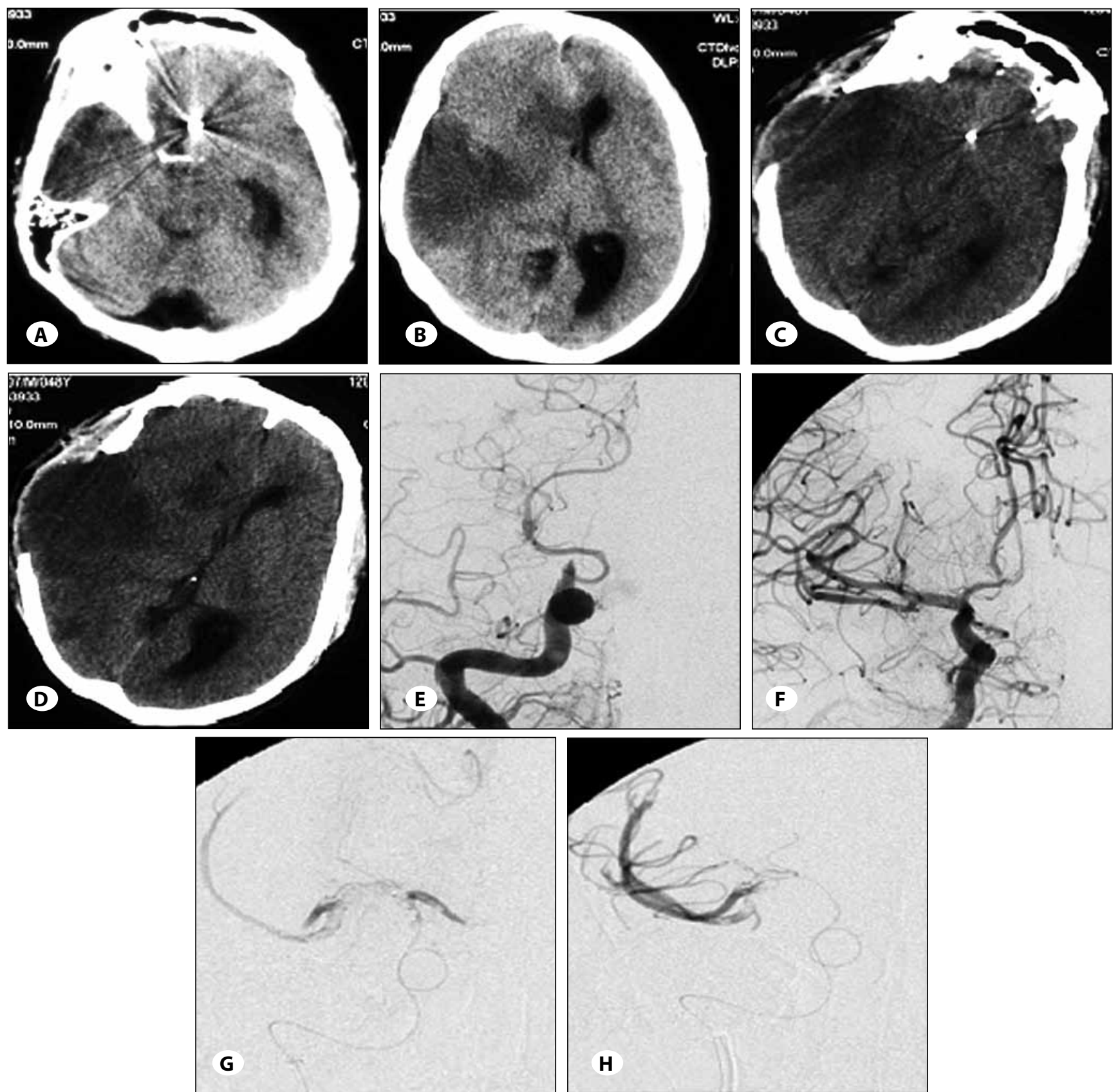

Figure 4: Partial recanalization, Gonner grade 2. A, B) Cranial CT performed $48 \mathrm{~h}$ after intra-arterial tirofiban + urokinase thrombolytic treatment shows cerebral infarction in the right temporoparietal lobe with obvious cerebral edema, midline shift, compression deformation of the lateral ventricle, and ventricular dilatation. C, D) Cranial CT performed one week after decompressive craniectomy shows mild brain edema, and compression deformation of the lateral ventricle with no hydrocephalus. E) Right internal carotid artery angiogram, anterior-posterior projection. Digital subtraction angiogram shows a filling defect in the clinoid segment of the right internal carotid artery. F) After intra-arterial infusion of tirofiban + urokinase via the microcatheter, angiogram shows resolution of the thrombus and patency of the artery. G, H) Intra-arterial infusion of tirofiban + urokinase via the microcatheter after passing through the thrombus. 


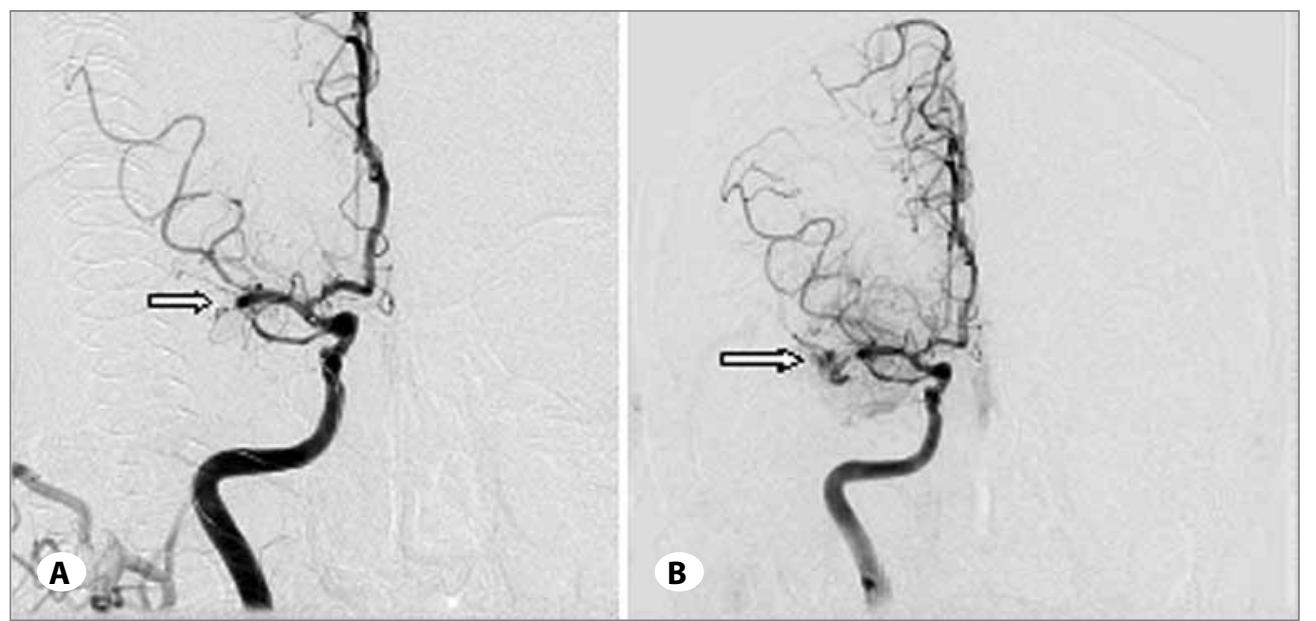

Figure 5: A case with Gonner grade 1 after loose packing of the aneurysm. A) Thromboembolus in the middle cerebral artery bifurcation (indicated by the arrow). B) After intraarterial infusion of tirofiban + urokinase, angiogram shows a ruptured aneurysm with a contrast leakage (indicated by the arrow). thrombolytic drugs is very low. Additionally, patients who are unresponsive to tirofiban have cardiovascular diseases which are associated with poor vascular condition. In this study, one 77-year-old patient exhibited partial recanalization of the M1 segment of the middle cerebral artery after the thrombolytic treatment. This patient exhibited mild hemiparalysis, and recovered well after the operation. However, the patient died of myocardial infarction while straining during defecation. This case suggests that systemic diseases, especially cardiovascular diseases, should be carefully managed in these patients during the recovery period.

Intracranial hemorrhage is a severe complication of intraarterial thrombolysis. It has been reported that the incidence rate of intracranial hemorrhage ranges from $10.9 \%$ to $32 \%$ with a mortality rate of $83 \%-86 \%$. In this study, intracranial hemorrhage occurred in 2 cases, or $14.3 \%$ of the patients. This incidence rate is consistent with the literature, and may be associated with the low dosage of tirofiban and urokinase used in this study. In one case with loose packing of the aneurysm, intracranial hemorrhage occurred due to a ruptured aneurysm during the thrombolytic treatment and the patient died. Therefore, intra-arterial tirofiban infusion should not be performed immediately unless sufficient aneurysmal protection with coils was achieved due to the risk of rebleeding. In the other case, an exudation of contrast agent was discovered during the operation, and cranial CT performed immediately found a hematoma in the left frontal lobe. The formation of hematoma was likely due to a puncture of the left posterior internal frontal artery caused by mechanical thrombolysis using a microguide wire.

Many authors have insisted that abciximab is effective and safe for thrombi during aneurysm coiling $(1,6)$. However other researchers have identified that intra-arterial abciximab could induce fatal hemorrhage $(11,16)$. In addition, operations such as decompressive craniectomy or external ventricular drainage are sometimes necessary after coil embolization, especially in cases of ruptured cerebral aneurysms. While abciximab inhibits platelet function for $48 \mathrm{~h}$ with a low- level blockade observed for up to 14 days, the plasma halflife of tirofiban is two hours and platelet function is almost normalized within four hours after discontinuation. On this account, tirofiban, which has a short plasma half-life and is a competitive inhibitor of glycoprotein Ilb/Illa, may be more suitable for treating thromboembolisms during coil embolization of cerebral aneurysms.

\section{CONCLUSION}

Our results indicate that intra-arterial administration of tirofiban plus urokinase is an effective and safe treatment for thromboembolism during coil treatment of ruptured cerebral aneurysms. However, because the sample size of this study is small, future studies with a large population of patients will be conducted to investigate the effects of intra-arterial tirofiban infusion and to determine the optimal dose of tirofiban.

\section{REFERENCES}

1. Aggour M, Pierot L, Kadziolka K, Gomis P, Graftieaux JP: Abciximab treatment modalities for thromboembolic events related to aneurysm coiling. Neurosurgery 67: 503-508, 2010

2. Baik SK, Oh SJ, Park KP, Lee JH: Intra-arterial tirofiban infusion for partial recanalization with stagnant flow in hyperacute cerebral ischemic stroke. Interv Neuroradiol 17:442-451, 2011

3. Cho YD, Lee JY, Seo JH, Kang HS, Kim JE, Jung KH, Han MH:Intraarterial tirofiban infusion for thromboembolic complication during coil embolization of ruptured intracranial aneurysms. Eur J Radiol 81: 2833-2838, 2012

4. Jeon JS, Sheen SH, Hwang G, Kang SH, Heo DH, Cho YJ: Intraarterial tirofiban thrombolysis for thromboembolisms during coil embolization for ruptured intracranial aneurysms. J Cerebrovasc Endovasc Neurosurg 14: 5-10, 2012

5. Jeong HW, Jin SC: Intra-arterial infusion of a glycoprotein llb/ Illa antagonist for the treatment of thromboembolism during coil embolization of intracranial aneurysm: A comparison of abciximab and tirofiban. AJNR Am J Neuroradiol 34: 1621-1625, 2013 
6. Kang HS, Han MH, Kwon BJ, Jung C, Kim JE, Kwon OK, Oh CW: Is clopidogrel premedication useful to reduce thromboembolic events during coil embolization for unruptured intracranial aneurysms? Neurosurgery 67:1371-1376; discussion 1376, 2010

7. Kwon BJ, Seo DH, Ha YS, Lee KC: Endovascular treatment of wide-necked cerebral aneurysms with an acute angle branch incorporated into the sac: Novel methods of branch access in 8 aneurysms. Neurointervention 7: 93-101, 2012

8. Lang SH, Manning N, Armstrong N, Misso K, Allen A, Di Nisio $M$, Kleijnen J: Treatment with tirofiban for acute coronary syndrome (ACS): A systematic review and network analysis. Curr Med Res Opin 28: 351-370, 2012

9. Mangiafico $S$, Cellerini $M$, Nencini $P$, Gensini G, Inzitari D: Intravenous glycoprotein Ilb/Illa inhibitor (tirofiban) followed by intra-arterial urokinase and mechanical thrombolysis in stroke. AJNR Am J Neuroradiol 26: 2595-2601, 2005

10. Ottani F, La Vecchia L, De Vita M, Catapano O, Tarantino F, Galvani M: Comparison by meta-analysis of eptifibatide and tirofiban to abciximab in patients with ST-elevation myocardial infarction treated with primary percutaneous coronary intervention. Am J Cardiol 106: 167-174.e1, 2010

11. Park JH, Kim JE, Sheen SH, Jung CK, Kwon BJ, Kwon OK, Oh $\mathrm{CW}$, Han $\mathrm{MH}$, Han DH: Intraarterial abciximab for treatment of thromboembolism during coil embolization of intracranial aneurysms: Outcome and fatal hemorrhagic complications. J Neurosurg 108: 450-457, 2008

12. Pelz DM, Lownie SP, Fox AJ: Thromboembolic events associated with the treatment of cerebral aneurysms with Guglielmi detachable coils. AJNR Am J Neuroradiol 19: 1541-1547, 1998
13. Rho MH, Kim BM, Suh SH, Kim DJ, Kim DI: Initial experience with the new double-lumen scepter balloon catheter for treatment of wide-necked aneurysms. Korean J Radiol 14: 832-840, 2013

14. Schiariti M, Saladini A, Cuturello D, Missiroli B, Puddu PE: Long-term efficacy of high-dose tirofiban versus doublebolus eptifibatide in patients undergoing percutaneous coronary intervention. J Cardiovasc Med (Hagerstown) 12: 29-36, 2011

15. Song TJ, Lee KO, Kim DJ, Lee KY: Rescue treatment with intraarterial tirofiban infusion and emergent carotid stenting. Yonsei Med J 49: 857-859, 2008

16. Walsh RD, Barrett KM, Aguilar MI, Lanzino G, Hanel RA, Miller DA, Chong BW, Freeman WD: Intracranial hemorrhage following neuroendovascular procedures with abciximab is associated with high mortality: A multicenter series. Neurocrit Care 15: 85-95, 2011

17. Won YS, Rho MH, Kim BM, Park HJ, Kwag HJ, Chung EC: Various techniques of stent-assisted coil embolization of wide-necked or fusiform middle cerebral artery aneurysms: Initial and mid-term results. J Korean Neurosurg Soc 53: 274-280, 2013

18. Workman MJ, Cloft HJ, Tong FC, Dion JE, Jensen ME, Marx WF, Kallmes DF: Thrombus formation at the neck of cerebral aneurysms during treatment with Guglielmi detachable coils. AJNR Am J Neuroradiol 23: 1568-1576, 2002 